\title{
Clinical-Statistical Study on the Use of a Magnesium-Terpene-Based Substance in Polymeric Trays for Periodontal Treatment
}

\author{
EDWIN SEVER BECHIR ${ }^{1}$, RUXANDRA VOINEA-GEORGESCU ${ }^{2 *}$, MIHAELA-JANA TUCULINA ${ }^{3}$, \\ IONELA TEODORA DASCĂLU ${ }^{* 3}$, DORA MARIA POPESCU ${ }^{3}$, MELANIA COJOCARU $^{3}$, \\ LELIA MIHAELA GHEORGHIȚĂ ${ }^{3}$, CRISTIAN-NIKY CUMPATA ${ }^{2}$, MIHAELA RĂESCU ${ }^{2}$, \\ ANCA GABRIELA GHEORGHE ${ }^{3}$ \\ ${ }^{1}$ Medicine, Pharmacy, Science and Technology University of Tirgu Mures, Faculty of Dental Medicine, 38 Gheorghe Marinescu Str., \\ 540142, Tirgu Mures, Romania \\ ${ }^{2}$ Titu Maiorescu University of Bucharest, Faculty of Dental Medicine, 67A Gheorghe Petrascu Str., 031593, Bucharest, Romania \\ ${ }^{3}$ Medicine and Pharmacy University of Craiova, Faculty of Dental Medicine, 2-4 Petru Rares Str., 200349, Craiova, Romania
}

Periodontal diseases are inflammatory diseases that cause lesions of the dento-periodontal system and can even lead to the loss of teeth. A successful treatment of periodontal diseases includes procedures aimed at reducing inflammation, by mechanical and chemical means, which have the role to decrease the pathogenicity of microorganisms found in the bacterial plaque. The study was conducted on a group of 50 patients, of whom a control group of 25 patients followed conventional periodontal treatment, while the other 25 patients received magnesium-terpene therapy by using polymeric thermoforming mouth custom trays, along with conventional periodontal treatment. The statistical and clinical assessment of the study revealed the efficiency of the magnesium-terpene active gel for the treatment of periodontal disease.

Keywords: Clinical-statistical study, magnesium-terpene-based substance, periodontal disease.

The local essential factor for the onset of periodontal disease is represented by a complex subgingival biofilm ecosystem, which contains a wide variety of microorganisms and their products. The bacteria and their toxins are able to enter the gingival tissues within the gingival sulcus, through micro-ulcerations and other epithelial lesions, causing an inflammatory reaction at this level [1]. When advancing towards the deeper periodontal structures, like the periodontal ligament and alveolar bone and if left untreated, this will result in the degradation of the periodontal tissues and tooth loss [2]. The purpose of periodontal therapy is to eliminate at best as possible the bacterial challenge to the periodontal tissues and to provide a clean and healthy local environment for the periodontal structures to regain functionality and integrity, as well as to allow the preservation of the teeth throughout the individual's life [3]. The disease prognosis through treatment depends on the ability of the patient and the dentist to control and eliminate the local etiological factor, the bacterial subgingival plaque. If biofilm accumulation and growth is controlled the gingival tissues could heal and regain their initial characteristics, as the inflammatory changes in gingivitis are reversible [4]. However, this is not the case for the situation when the inflammatory reaction reaches the periodontal ligament or alveolar bone, where it inflicts permanent, irreversible damage [5-9]. If the etiological factor is not thoroughly controlled, the prognosis is unfavourable, as there is a high probability of incomplete inflammation remission or future disease relapse. If the inflammatory process persists, it will expand to the profound elements of the periodontium, resulting in periodontitis [10]. The treatment of periodontal disease is a continuous challenge, with each clinical case having its specificity. The conventional treatment method involves manual and ultrasonic supra and subgingival scaling and root planning with Gracey's curettes, so as to ensure a most comprehensive removal of the bacterial biofilm, as possible [11]. The mechanical removal of the biofilm is aided with the use of local antimicrobial substances. These chemical agents target bacterial cells, disabling their metabolism or their coalescent capabilities [12]. These locally applied substances include antibiotics (tetracycline, doxycycline etc) and antiseptics (Chlorhexidine, Triclosan, Sanguinarine, a.s.). These antiseptic substances can be found and used under different variants: solutions and oils for rinsing and irrigations, gels for local dabbing) [13]. The use of chemical and surgical methods completes the protocol of the comprehensive treatment strategy

*email: ruxi0372@yahoo.com; marceldascalu@yahoo.com All the authors equally contributed to the drawing up of the present paper 
applied to the patients with periodontal affections, according to the evolution stage of the disease [14], deposited in polymeric thermoforming mouth custom trays [15].

The aim of this study was to assess the clinical efficiency of a magnesium-terpene-based gel by using polymeric thermoforming mouth custom trays, as a local antiseptic agent for plaque control in patients with periodontal disease.

\section{Experimental part}

\section{Materials and method}

The study, unfolding between March 2016 and April 2017, included 50 periodontal patients, aged between 18-55 years old. The study's participating patients were randomly divided into two separate groups that were not matched for demographic characteristics. The working group, consisting of 25 patients, was treated with locally-applied magnesium-terpene-based gel, as part of nonsurgical periodontal therapy, as well as mechanical (ultrasonic and manual) removal of the subgingival biofilm. The control group of the other 25 patients followed conventional mechanical nonsurgical periodontal therapy. At the initial visit, patients completed the informed consent of participation in the study. The study was conducted in accordance with ethical standards of medical research and GDPR (Global Data Protection) and obtained the approval of the Ethics Committee of the Faculty of Dentistry of the "Titu Maiorescu" University in Bucharest.

All patients selected for the study were diagnosed with uncomplicated simple bacterial gingivitis on the basis of the subjective and objective clinical symptoms, periodontal probing values and radiological examination. During the objective clinical examination all patients showed signs of gingival inflammation, including colour changes to intense redness and gingival bleeding when probing. Subjectively, patients were bleeding upon brushing and had halitosis. The data collected during the clinical examination was recorded using observation sheets, including the value of the GI (Gingival Index) and PBI (Papillary Bleeding Index). The Gingival Index uses the clinical manifestations of gingival inflammation (changes in gingival colour, spontaneous gingival bleeding or on probing, oedema) in order to quantify the gingival status with scores from zero (normal gingival) to three (severe inflammation). The PBI uses scores from zero (absence of bleeding) to four (profuse bleeding) to quantify the degree of gingival bleeding occurring after periodontal probing, within the gingival papilla.

Conventional treatment for the diagnosed gingivitis consisted of ultrasonic cleaning, followed by air flow and professional brushing with an abrasive paste. These treatment methods were applied to the entire group of 50 patients. The patients of the control group were trained for home hygiene and brushing methods, while the patients of the working group were applied the magnesium-terpene-based gel substance. For each of the patients in the working group dental impressions were recorded for the manufacturing of thermoforming polymeric custom tray, needed for the application of the gel. The areas of the interdental papilla were protected by creating discharge areas. Each patient received the custom bite guards for home use and also the magnesium-based gel substance in a quantity sufficient for 4 weeks of treatment. For the next 30 days after the initial clinical examination, the patients had to follow certain indications: keeping good oral hygiene; application of the gel into the $\mathrm{t}$ thermoforming polymeric custom tray; inserting the thermoforming custom tray onto the teeth and keeping it for one hour daily, for 30 days; avoid eating, drinking or smoking during the 60 minutes of treatment. After two weeks of home treatment, all patients were invited to recall. During these intermediary appointments, patients were asked about any side effects and the modality and frequency of use, while receiving sufficient amounts of gel for the remaining weeks of treatment. No treatment was performed during these intermediate meetings.

After the 30 days of home treatment, all patients were invited to an appointment, during which the new clinical parameters were recorded, including visible signs of gingival inflammation, the gingival index and papillary bleeding index. As eight patients did not return to the dental office for the one month recall visit, they were excluded from the study. Seven of these patients belonged to the working group, while one was part of the control group. When this clinical examination was completed, the patients were discharged and asked to return after 11 months (12 months from the initial visit) for another clinical evaluation of their periodontal status.

\section{Results and discussions}

After 14 days of the initial visit and periodontal treatment debut, there was a reduction in gingival inflammation and bleeding levels in the patients of the working group and an improvement in patients of the control group. After 30 days of the initial visit and periodontal treatment debut, we observed a significant 
decrease of the intensity of the acute and post-operative symptoms. Patients were monitored for one year, both clinically and radiological (Fig. 1).

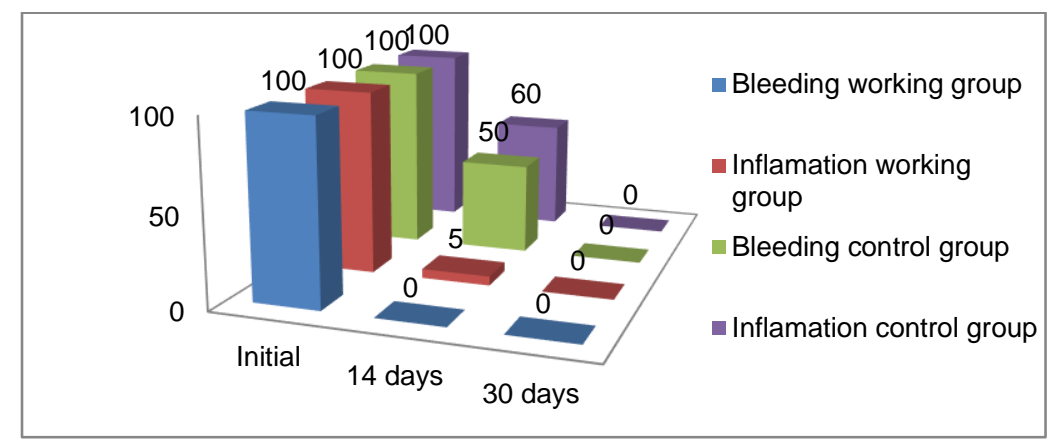

Fig. 1. The evolution of inflammation and bleeding at 14-30 days for study groups-blank check

During the one year recall, for 38 patients (52\%), the periodontal disease ceased to evolve after treatment and the improvement in oral hygiene, the absence of gingival inflammation and of spontaneous/on probing bleeding ( $\mathrm{GI}=0 ; \mathrm{PBI}=0)$ was observed. In eight patients $(32 \%)$, the periodontal disease progressed to PMCS (Superficial Chronic Marginal Periodontitis). Of these eight patients only one of them (4\%) was part of the working group, while the other seven $(28 \%)$ were from the control group (GI=2; PBI=2). For these eight patients, initial therapy was supplemented with subgingival root planning, associated with the application of the same active substance. During the one year recall, four patients (16\%), with poor hygiene, were rediagnosed with PMCP (Deep Chronic Marginal Periodontitis) $(\mathrm{GI}=3 ; \mathrm{PBI}=4)$ and surgical treatment was recommended (open-field curettage using the papillary microflaps technique) (Fig. 2; Fig. 3).



Fig. 2. The evolution of periodontal disease in conventionally treated patients (control group) after 1 year

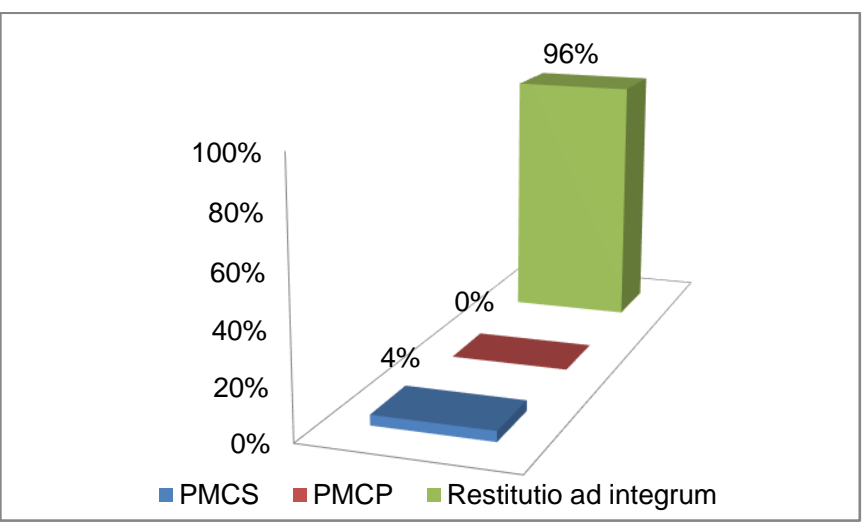

Fig. 3. The evolution of periodontal disease in the working group, after 1 year (treated conventionally and with magnesium-terpene gel in thermoforming polymeric custom trays)

Of the control group 13 patients (52\%) turned to restitutio ad integrum, seven patients (28\%) developed PMCS and four patients (16\%) developed PMCP. 
As part of the efforts to find non-interventional treatment solutions for severe gum disease, different substances have been developed. A group of Israeli physicians were first to describe observations of patients whose periodontal condition improved as a result of the local use of the magnesium-terpene-based gel [16]. Similar results were obtained by our study, the evolution of periodontal disease being highly influenced by the oral hygiene of the patients, with female patients being more concerned with this aspect. Based on the first observations of the Israeli study, wider clinical observations were performed on a group of patients diagnosed as suffering from periodontal disease, which was not a controlled clinical trial, but a long-term observation of a patient population, including other antiseptic substances gels [17]. Following laboratory experiments, it is possible to assume that the combination of magnesium-terpene components of the gel in question gives a synergistic effect of these two anti-inflammatory and antioxidant (anti-oxidant) substances [18]; it has also been shown that this combination has a strong antiseptic (antiseptic) effect, even at low doses. In areas of inflammation, the gel appears to function as a mechanism for delaying histamine release from mast cells, induces blood capillary formation, and also induces bone regeneration [19]. [20].

An important factor for stopping the development of gingivitis is the proper performance of initial therapy

The results of the study show that, through personal magnesium-terpene gel treatment, significant results were obtained in reducing gingival bleeding and visibly improving the status of the periodontium. The patients of the working group wanted to use this gel deposited in the polymeric trays for the therapy of their periodontal disease.

The study highlights the efficacy of periodontal treatments that use the magnesium-terpene-based gel applied in oral cavity, by using thermoforming polymeric custom trays, as an adjunct to the conventional method, in terms of improvement of clinical parameters, such as gingival index and probing bleeding index.

\section{Conclusions}

This method of treatment, based on the use of the magnesium-terpene gel deposited in thermoforming polymeric trays, is simple to apply.

The obtained results showed an improvement of all tested standards in patient groups.

No side effects have been reported.

Compared to the control group, patients in the working group presented a faster cure and a lack of relapse.

\section{References}

1.TELES, R, TELES, F, FRIAS-LOPEZ, J, PASTER, B, HAFFAJEE, A, Periodontol 2000, 2013, 62(1):95-162.

2.SILVA, N, ABUSLEME, L, BRAVO, D, DUTZAN, N, GARCIA-SESNICH, J, VERNAL, R, GAMONAL, J. J Appl Oral Sci, 2015, 23(3):329-355.

3.DENTINO, A, LEE, S, MAILHOT, J, HEFTI, AF. Periodontol 2000, 2013, 61(1):16-53.

4.GRAZIANI, F, KARAPETSA, D, ALONSO, B, HERRERA, D. Periodontol 2000, 2017, 75(1):152-188.

5.CAVALLA, F, BIGUETTI, CC, GARLET, TP, TROMBONE, APF, GARLET, GP. Inflammatory pathways of bone resorption in periodontitis. In Pathogenesis of Periodontal Diseases, Springer, Cham. 2018, 59-85.

6.BECHIR, E.S., PACURAR, M., HANTOIU, T.A., BECHIR, A., SMATREA, O., BURCEA, A., GIOGA, C., MONEA, M., Rev. Mat. Plast., 53, no. 1, 2016, p. 104

7.JIMBOREAN, G., IANOSI, E.S., CSIPOR, A., POSTOLACHE, P., Rev. Chim. (Bucharest), 68, no. 9. 2017, p. 2129.

8.CIAVOI, G., TIRB, A., BECHIR, E.S., BECHIR, F., SUCIU I., Rev. Chim. (Bucharest), 69, no.10, 2018, p. 2648.

9.ODOR, A.A., BECHIR, E.S., VIOLANT, D., BADEA, V., Rev. Chim. (Bucharest), 69, no.8, 2018, p. 2081.

10.KAYAL, RA. Biomed Res Int. 2013;2013:639368.

11.KRISHNA, R., DE STEFANO, JA. Periodontol 2000, 2016, 71(1):113-127.

12.AIMETTI, M. Int J Esthet Dent, 2014, 9(2):251-267.

13.LESZCZYŃSKA, A, BUCZKO, P, BUCZKO, W, PIETRUSKA, M. Adv Med Sci, 2011, 56(2):123-131.

14.HERRERA, D, MATESANZ, P, BASCONES-MARTÍNEZ, A, SANZ, M. J Evid Based Dent Pract, 2012, 12(3), 50-60.

15.BECHIR, E.S., BECHIR, A., ARGHIR, O.C., CIAVOI, G., GIOGA, C., BECHIR, F., DASCALU, I.T., Rev. Mat. Plast., 54, no.2, 2017, p. 304

16.WOLNERMAN, JS, BERGMAN, Z, ZINI, A, MIZRAHI, B, VERED, Y, DOMB, AJ, MANN, J. Refu'at ha-peh veha-shinayim (1993), 2004, 21(2):72-7.

17.COSYN, J, SABZEVAR, MM. J Periodontol, 2005, 76(11):1805-1813.

18.SONTIA, B, TOUYZ, RM. Arch Biochem Biophys, 2007, 458(1):33-39.

19.THOLL, D. Curr Opin Plant Biol, 2006, 9(3):297-304.

20.SAITO A, HOSAKA Y, KIKUCHI M, AKAMATSU M, FUKAYA C, MATSUMOTO S, NAKAGAWA, T. J Periodontol, 2010 , 81(7):1001-1009.

Manuscript received: 25.09 .2019 